\title{
Lithium industry and the U.S. crude oil prices. A Fractional Cointegration VAR and a Continuous Wavelet Transform analysis
}

\author{
Manuel Monge \\ Universidad Francisco de Vitoria (UFV), Department of Economics and Business \\ Spain
}

Luis A. Gil-Alana

University of Navarra, Faculty of Economics and ICS, Pamplona, Spain Universidad Francisco de Vitoria (UFV), Department of Economics and Business Spain

\begin{abstract}
This paper analyzes the dynamics of U.S. lithium mining companies, the lithium industry and West Texas Intermediate (WTI) crude oil prices using a Fractional Cointegration Vector AutoRegressive model (FCVAR model) and a Continuous Wavelet Transform (CWT) for its resolution. The results indicate evidence of a negative relationship between FMC Corp with Albermale and SQM stock prices. These results are similar if we analyze the risk based on the beta term structure of each company. Analyzing the fractional differencing parameter for the stock prices and their logs, we observe that they are very persistent, and there are no long-term deviations in the stock prices. The same happens when analyzing the beta term structure. Based on Continuous Wavelet Transform (CWT) methods, our results show that lithium mining companies and the lithium industry are weakly correlated with WTI crude oil prices at higher frequencies (short-run) and persist through the sample period. At lower frequencies (long-term) the time series reached a high level of dependence between late 2012 to mid 2016, concluding that the lithium mining companies and the lithium industry reflect and foreshadow the responsiveness of the WTI crude oil prices during the period mentioned above.
\end{abstract}

Keywords: Lithium industry; WTI oil prices; fractional cointegration; FCVAR model; wavelet analysis.

JEL Classification: C00; C22; E30; Q40;

Corresponding author: Dr. Manuel Monge

Universidad Francisco de Vitoria (UFV)

Faculty of Law and Business

E-28223 Madrid

Spain

Email: manuel.monge@ufv.es

Luis A. Gil-Alana gratefully acknowledges financial support from the Ministerio de Economía y Competitividad (ECO2017-85503-R). Both authors also acknowledged support from an internal Francisco de Vitoria University project. Comments from the Editor and two anonymous reviewers are gratefully acknowledged. 


\section{Introduction}

Oil and lithium are two commodities that represent current and expected future energy supply, respectively. Since the late 19th century, the dominant source of energy has been that which has powered vehicles, from steam to gasoline to electrical power (see Anderson and Anderson, 2010). Most of the world liquid fuel is in the transport sector, and according to IPCC (2007), this sector produces $70 \%$ of total greenhouse gases. The interest in adopting renewables energies to stem the increase in global warming and climate change is increasing in recent years, especially in the automotive sector.

The Paris agreement, ratified by many countries around the world, including ten OPEC member countries has endeavoured to focus on energy storage and electric mobility. That is why lithium and its industry play a fundamental role, given that lithium is the fundamental metal in the production of batteries for electric vehicles (EVs). The interest in increasing the use of electric vehicles to the detriment of combustion vehicles to achieve the aforementioned climate objectives, makes us think about an energy transition that may bring about residual use or the near disappearance of fossil fuels, at least in the transport sector.

According to Schurr and Netschert (1960), two energy transitions have occurred in the US; the first when the use of coal overtook that of wood as a source of fuel in 1895 , with $65 \%$ of coal versus $30 \%$ of wood, and the second, four and a half decades later involving oil and gas, when coal represented 28 percent and oil and gas $65 \%$. In a recent paper, Cherif and Hasanov (2017) argue that, as in the previous cases, the same could happen to oil with renewable energies in relation to the transport sector in the next 10 to 25 years.

[Figure 1 about here] 
Figure 1 is related to the statement made by Hao et al. (2016) where the increase in global demand for electric vehicles results in an increase in lithium consumption. We see in the figure that $56 \%$ of global end-use lithium markets are used to for batteries. The arguments cited above may have an impact on the crude oil prices due to the technological transition process and climate policy implications (Nakicenovic, 1986; Sovacool, 2016; Fouquet, 2016, among others). There are other authors who argue that the use of fossil energies can still persist thanks to the effect and production of shale oil in the United States (see Fouquet, 2010). Monge et al. (2017) showed that there was a structural change with the appearance of shale oil in January 2004. They also studied the behaviour of production and prices of shale oil, finding evidence of mean reversion during the prebreak period and lack of it after the break. PwC (2016) predicts moderate growth of vehicle sales for North America while emerging markets are expected to exhibit a steeper sales growth in light vehicles over the next decade. The new regulations, subsidies and technological advances are expected to increase the sale of electric cars, counteracting the impact of oil prices on the automobile industry.

To answer the question about what type of relationship exists between the lithium industry and how it affects crude oil prices, we have made a short review of the literature.There are several studies focusing on the metal industry and the movement of prices. Ciner (2001) examines the long-run trend in gold and silver contracts traded on the Tokyo Commodity Exchange using cointegration methods, concluding that each should be approached as separete markets. Dooley and Lenihan (2005) analyzed future lead and zinc prices using ARIMA models. Auer (2015) used GARCH models to investigate precious metal markets focused on gold, silver, palladium and platinum, finding evidence of time-varying skewness and kurtosis in precious metals returns. Labys et al. (1998), using a Weibull test of cyclical duration for discovered cycles and a 
structural time series method, analyzed short-term prices for aluminum, copper, gold, lead, nickel, silver, tin, tungsten, and zinc. Rossen (2015) explored the long- and shortrun cyclical behaviour of 20 monthly price series of a variety of mineral commodities such as copper, lead, tin, zinc, chromium, cobalt, manganese, etc. in the last 100 years, concluding that metal prices increase more strongly in a shorter period than they fall and they do not necessarily follow similar patterns. Sari et al. (2010) studied how gold, silver, platinum, palladium, oil prices and the U.S. dollar/euro exchange rate co-move and transmit information, finding a weak long-run equilibrium relationship, but strong feedbacks, in the short-run. Apergis et al. (2014), using a FAVAR model concluded that the price transmission across precious metal markets, stock markets, and the macroeconomy is substantial. Mo and Jeon (2018) examined cobalt, lithium, nickel and manganese prices with EV demand using the Vector Error Correction Model (VECM) method, finding that evidence of EV demand is important in short-run dynamics of cobalt and lithium prices. Other research papers in this context include Freitas and Da Silva (2013) and Martin et al. (2017), among others. Berthelsen and Arteaga (2016) studied the relationship between oil prices, lithium prices and electric vehicle growth using a VECM approach. They conclude that the most robust model was that in which the target equation was the lithium prices, showing that there is a long run relationship between the variables. They also concluded that causality is mostly from EV sales and oil prices towards lithium prices.

Following the research line initiated by Monge and Gil-Alana $(2018,2019,2020)$ and Gil-Alana and Monge (2019), to our knowledge, this is the first research paper which endeavours to analyze the impact of the lithium industry on the crude oil price in the U.S. and to determine what kind of relationship exists between them in the long run. To do so, first we analyze their statistical properties measuring the degree of persistence by using 
fractional integration techniques and examing the long-term relationship of the three most important lithium mining stocks, which are Albemarle, SQM (Sociedad Química y Minera de Chile) and the FMC Corporation ${ }^{1}$ that operates on the New York Stock Exchange (NYSE), and their beta term structure using the Fractional Cointegration VAR (FCVAR) model proposed in Johansen and Nielsen (2010, 2012). Finally, we use methodologies based on Continuous Wavelet Transform (CWT) such as those in Davidson et al. (1997), Yousefi et al. (2005), Connor and Rossiter (2005), Vacha and Barunik (2012), Monge and Gil-Alana 2020, among others, to analyze structural changes in WTI crude oil prices caused by the U.S. and Chile lithium mining companies, which represent $46 \%$ of the market ${ }^{2}$, and the lithium industry represented by Solactive Global Lithium Index in the time frequency domain. For this purpose we have used daily, weekly and monthly data.

The rest of the paper is organized as follows. Section 2 describes the data and presents the methodology applied in the paper. In Section 3 we discuss the main empirical results, while Section 4 concludes the paper.

\section{Data and methodology}

\subsection{Dataset}

The choice of our dataset of lithium companies is based on the fact that they are among the largest lithium mining companies per market capitalization, market share and are listed in the stock markets. This criterion ensures that the chosen firms will be among the largest players on the market and their stocks will be highly liquid. Following this criterion, our final dataset includes the three largest U.S. lithium companies, namely,

\footnotetext{
${ }^{1}$ FMC's decision to spin out and rename its lithium business Livent Corporation in 2018 means FMC is now focused on agricultural products.

${ }_{2}^{2}$ Information related to market share was obtained from IG for 2019 (https://www.ig.com/uk/trading-strategies/what-are-the-bestlithium-stocks-to-watch--200824).
} 
Albemarle, FMC Corp and SQM. Table 1 describes the market capitalization and market share of the selected companies.

\section{[Insert Table 1 about here]}

We use daily data due to the richer information provided (see Bannigidadmath and Narayan, 2016; Pal and Mitra, 2019). Other frequencies such as weekly or monthly have also been used in this analysis. The dataset is obtained from Thomson Reuters Eikon database and covers the period from 16th July 2010 to 14th March 2019³. Data are expressed in US dollars. ${ }^{4}$

We use the exchange index (New York Stock Exchange) to calculate the daily, weekly and monthly beta of each company ${ }^{5}$. According to Momcilovic, et al. (2014) there are no statistically significant differences between betas calculated on the basis of daily, weekly and monthly return intervals, something we also show in the present work. For the lithium industry, we use the Solactive Global Lithium Index and to represent crude oil prices in the United States we use WTI crude oil prices.

\subsection{Unit roots methods}

There exist many different ways of testing for unit-roots. The most common ones are those of Fuller (1976) and Dickey and Fuller (1979), the ADF tests. They are asymptotically optimal when the data are stationary. Other unit root methods are those proposed in Phillips and Perron (PP, 1988), Kwiatkowski et al. (KPSS, 1992) and Elliot et al. (ERS, 1996) and more recently by Ng and Perron (NP, 2001) and others. The unit

\footnotetext{
${ }^{3}$ The reason to use the selected time period is that according to Kilian (2016) and Monge et al (2017), in March 2014, the United States economy produced on average 8.2 million of barrels/day (mbd) and imported $7.3 \mathrm{mbd}$. Thus, from this date, United States displaced the Arab oil producing countries and with their crude oil exports (see Kilian, 2017), became a net exporter. This is an interesting reason to see how the lithium industry, linked to the manufacture of batteries for hybrid and electric cars, affects the price of WTI oil. According to BP (2017), most of the world liquid fuel is employed in the transport sector.

${ }^{4}$ The data that support the findings of this study are available from the authors upon request.

${ }^{5}$ We have calculated the beta term as the division between the covariance of the return on the asset and the market, divided by the variance of the return on the market.
} 
root methods were later extended to the fractional case by authors such as Gil-Alana and Robinson (1997) and numerous authors have found the low power of classical unit root tests if the alternatives are of a fractional form (Diebold and Rudebusch, 1991; Hassler and Wolters, 1994; Lee and Schmidt, 1996; etc.). The natural generalization of fractional integration to the multivariate case refers to the concept of fractional cointegration also presented below.

\subsection{ARFIMA (p, d, q) model}

We employ in this research long memory methods based on fractional integration, where the number of differences required to render a series $\mathrm{I}(0)$ stationary is fractional. Following a mathematical notation, given a time series $x_{t}$, where $t=1,2, \ldots$, it is said to be integrated of order $\mathrm{d}$ (and denoted as $x_{t} \approx I(d)$ ) if

$$
(1-L)^{d} x_{t}=u_{t}, \quad t=1,2, \ldots
$$

where $d$ can be any real value, $L$ is the lag-operator $\left(L x_{t}=x_{t-1}\right)$ and $u_{t}$ is $\mathrm{I}(0)$, defined as a covariance stationary process with a spectral density function that is positive and finite at the zero frequency. Thus, $u_{t}$ may display some type of time dependence of the weak form, i.e., the type of an Autoregressive Moving Average (ARMA) form such that, for example, if $u_{t}$ is ARMA (p, q), $\mathrm{x}_{\mathrm{t}}$ is said to be ARFIMA ( $\left.\mathrm{p}, \mathrm{d}, \mathrm{q}\right)$.

Depending on the value of the parameter $d$, several specifications based on (1) can be observed. The process would be short memory or I(0) when $d=0$ in (1). This occurs because $x_{t}=u_{t}$. The high degree of association between observations which are far distant in time receives the name of long memory and occurs when $d>0$. Within this last assumption, the process is still covariance stationary if $d<0.5$ and the autocorrelations decay hyperbolically fast. An interpretation that we can make on the value of $d$ is that a process presents mean reversion with shocks disappearing in the long 
run if $d$ is smaller than 1 . In contrast to the above, shocks are expected to be permanent when $d \geq 1$.

Although there are several procedures to estimate the degree of long memory and fractional integration (see Geweke \& Porter-Hudak, 1983; Phillips, 1999, 2007; Sowell, 1992; Robinson, 1994: 1995; etc.). We base our results on the maximum likelihood procedure (see Sowell, 1992) and use Akaike information criterion (AIC, Akaike, 1973) and Bayesian information criterion (BIC; Akaike, 1979) to select the right ARFIMA model.

\subsection{Fractional Cointegrated VAR}

Johansen (2008) introduced a method to check for a multivariate fractional cointegration model denominated Fractionally Cointegrated Vector AutoRegressive (FCVAR), and Johansen and Nielsen $(2010,2012)$ expanded it. It is a step forward on the Cointegrated Vector AutoRegressive model (Johansen, 1996), named CVAR, and it allows for series which are integrated of order $d$ and that cointegrate with order $d-b$, with $b>0$. To introduce the FCVAR model, we should start first by refering to the non-fractional CVAR model.

Let $Y_{t}, t=1, \ldots, T$ be a p-dimensional $\mathrm{I}(1)$ time series. The CVAR model is:

$$
\Delta Y_{t}=\alpha \beta^{\prime} Y_{t-1}+\sum_{i=1}^{k} \Gamma_{i} \Delta Y_{t-i}+\varepsilon_{t}=\alpha \beta^{\prime} L Y_{t}+\sum_{i=1}^{k} \Gamma_{i} \Delta L^{i} Y_{t}+\varepsilon_{t}
$$

To derive the FCVAR model we must replace the difference and lag operators by $\Delta^{b}$ and $L_{b}=1-\Delta^{b}$, respectively. We then obtain:

$$
\Delta^{b} Y_{t}=\alpha \beta^{\prime} L_{b} Y_{t}+\sum_{i=1}^{k} \Gamma_{i} \Delta L_{b}^{i} Y_{t}+\varepsilon_{t}
$$

which is applied to $Y_{t}=\Delta^{d-b} X_{t}$ such that

$$
\Delta^{d} X_{t}=\alpha \beta^{\prime} L_{b} \Delta^{d-b} X_{t}+\sum_{i=1}^{k} \Gamma_{i} \Delta^{b} L_{b}^{i} Y_{t}+\varepsilon_{t},
$$


where $\varepsilon_{t}$ is p-dimensional independent and identically distributed, with mean zero and covariance matrix $\Omega$. From the CVAR model we can interpret the parameters. Thus $\alpha$ and $\beta$ are $p \times r$ matrices, where $0 \leq r \leq p$. The columns of $\beta$ are the cointegrating relationships in the system, that is to say the long-run equilibria. $\Gamma_{i}$ is the parameter that governs the short-run behaviour of the variables. The coefficients in $\alpha$ represent the speed of adjustment responses to deviations from the equilibria and the short-run dynamics of the system.

Matlab computer programs, provided by Nielsen and Popiel (2018) for the calculation of estimators and test statistics in the FCVAR model, have been employed in numerous empirical papers (Baruník and Dvořáková, 2015; Maciel, 2017; Aye et al., 2017; Dolatabadi et al., 2018; Jones, Nielsen and Popiel, 2018; Gil-Alana and Carcel, 2018; etc.).

\subsection{Wavelet Analysis}

The wavelet methodology is used to analyse time series in the time-frequency domain. Following Vacha and Barunik (2012), Aguiar-Conraria and Soares (2011, 2014), Dewandaru et al. (2016), Tiwari et al. (2016), Jammazi et al. (2017), and others who apply Continuous Wavelet Transform (CWT) in finance and economics research, two tools are used in this paper: wavelet coherency and wavelet phase-difference.

There are various reasons for using this methodology: first, stationarity is not a requirement to carry out a wavelet analysis and, second, it is interesting to study the interaction of both the time and the frequency domains of the time series themselves to find evidence of the potential changes in its pattern. Kyrtsou et al. (2009) presented evidence showing that several energy markets display consistent non-linear dependencies. Based on their analysis, the authors call for non-linear methods to analysis 
the impact of oil shocks. Wavelet analysis is one such method. We should also note that wavelets have already proven to be insightful when studying business cycles synchronizations, e.g. see Aguiar-Conraria and Soares (2014) and Crowley and Mayes (2008). In addition, the economic time series are an aggregation of components operating on different frequencies and we need the frequency information because the most distinguished information is hidden in the frequency content of the signal. Finally, the application of the usual cross-correlation to investigate statistical relationships between two multifractal time series often produces misleading results. (see Zhou 2008; Podobnik and Stanley 2008; Gu and Zhou 2010; Jiang and Zhou 2011).

The wavelet coherency plot is a two-dimensional diagram that correlates time series and identifies hidden patterns or information in the domain of time and frequency. The $W T_{x}(a, \tau)$ of a time series $x(t)$, that is obtained by projecting a mother wavelet $\psi$, is defined as:

$$
W T_{x}(a, \tau)=\int_{-\infty}^{+\infty} x(t) \frac{1}{\sqrt{a}} \psi^{*}\left(\frac{t-\tau}{a}\right) d t
$$

where $W T_{x}(a, \tau)$ are the wavelet coefficients of $x(t)$; the position of a wavelet in the frequency domain is defined by $a$, and $\tau$ is the position in the time domain. Thus, the wavelet transform provides information concurrently on time and frequency by mapping the original series onto a function of $\tau$ and $a$. The Morlet wavelet has been chosen as a mother wavelet to carry out our analysis since it is a complex sine wave within a Gaussian envelope, and thus we will be able to measure the synchronism between time series. (see Aguiar-Conraria and Soares, 2014 for the properties of this wavelet).

To understand the interaction and the integration between the two series we use the wavelet coherence defined as:

$$
W C O_{x y}=\frac{\operatorname{So}\left(W T_{x}(a, \tau) W T_{y}(a, \tau)^{*}\right)}{\sqrt{\left.\operatorname{So(}\left|W T_{x}(a, \tau)\right|^{2}\right) S o\left(\left|W T_{y}(a, \tau)\right|^{2}\right)}},
$$


where $S O$ is a smoothing operator in both time and scale. Without the smoothing operator, the wavelet coherency would always be one for all times and scales (see Aguiar-Conraria et al. (2008) for details). Matlab computer programs for the calculation of estimators and test statistics in the CWT are provided in Aguiar-Conraria's website ${ }^{6}$.

\section{Empirical Results}

We start the analysis by performing the three standard unit root tests outlined in Section 2. We select the Augmented Dickey-Fuller test (ADF), Phillips and Perrron (PP, 1988) and Kwiatkowski et al. (KPSS, 1992) to examine the statistical properties of the original series and its differences to obtain robust results. Table 2 displays the results, which suggest that the original data are nonstationary $\mathrm{I}(1)$ in the original values and thus $\mathrm{I}(0)$ stationary in its first differences.

\section{[Insert Table 2 about here]}

Identical results are obtained if other more updated unit root methods are used, such as those mentioned in the previous section. Employing the fractional integration approach, Table 3 displays the results of the ARFIMA (p, d, q) models. ${ }^{7}$

\section{[Insert Table 3 about here]}

We observe in Table 3 that the results are very similar for the three data frequencies used (daily, weekly or monthly). We observe that the behaviour of the beta of the company FMC supports the I(1) hypotheis, while the betas of the companies Albermarle and SQM are $\mathrm{I}(\mathrm{d} ; \mathrm{d}<1)$, implying fractional integration and a mean reverting behaviour, with shocks having temporary effects and disappearing by themselves in the long run.

\footnotetext{
${ }^{6} \mathrm{https}: / /$ sites.google.com/site/aguiarconraria/joanasoares-wavelets

${ }^{7}$ The configurations that we have made of the ARFIMA model have been "( $(0, \mathrm{~d}, 0)$ ", "(1, d, 0)", "(2, d, 0)", "(0, d, 1)", "(0, d, 2)", "(1, d, 1)", "(1, d, 2)", "(2, d, 1)", "(2, d, 2)". The selection criteria have been the AIC and BIC.
} 
The next step is to calculate the FCVAR model proposed by Johansen and Nielsen (2012), this is the classical CVAR model extended to fractional integration in order to contrast the possible existence of persistence in the spread. Considering that an overly long lag length could distort the data and lead to a decrease in the estimation power, we have followed Jones, Nielsen and Popiel (2014) by using a lag value $k=3$. We also follow two additional elements in the specification of the FCVAR model: the deterministic components and the cointegration rank $(r)$. In this paper, we impose $d=b$ in equation (3).

\section{[Insert Table 4 about here]}

Table 4 displays the estimated parameters. Panels I - III refer to the daily data; Panels IV - VI to weekly and VII - IX to monthly data. We observe from Panels I and II that the values of the fractional differencing parameter of this cointegrating structure are $0.980(0.024)$ and $0.985(0.024)$ respectively for the unlogged and logged data, meaning that the series are clearly non-stationary and close to $\mathrm{I}(1) .{ }^{7}$ Note that since we impose $\mathrm{d}=$ $\mathrm{b}$ in the model, the residuals must be $\mathrm{I}(0)$ and thus, cointegration errors are mean reverting, meaning that in the long term there are no deviations in the stock prices. On the other side, Panel III shows us the fractional differencing parameter of the beta term structure is $0.828(0.013)$, implying a smaller degree of integration but still in the nonstationary region, though now being mean reverting. Using weekly and monthly data the results are similar to the daily case and we cannot reject the hypothesis of I(1) in any of the panels examined in Table 4. Thus, we find the same behaviour again, regardless of the time frequency used for the calculation.

In order to check whether the strength of correlation and co-movement have varied before and after the crisis period we also test the existence of possible structural

\footnotetext{
${ }^{7}$ These results are in line with the literature (see for example Baruník \& Dvoráková, 2015) in which the asset prices are considered integrated of order 1, i.e. I(1).
} 
breaks in crude oil prices, following Pal and Mitra (2018). For this purpose, we use Perron and Vogelsan (1992) and Bai and Perron (2003) approaches for detecting breaks in the data. In addition, Gil-Alana's (2008) method, which extends the previous methods to the fractional case was also employed. The results were almost identical in the three cases.

The break dates, for the daily case are reported in the third colum of Table 5 where we observe 5 structural breaks, identified at the following periods: 02.11.2011; 26.06.2013; 27.11.2014; 13.05.2016, and 02.11.2017

\section{[Insert Table 5 about here]}

Next we perform the FCVAR analysis for each of the subsamples according to the breaks displayed in Table 5. The results are presented in Tables 6, 7 and 8, respectively for the stock prices, logged stock prices and the beta term.

\section{[Insert Tables 6, 7 and 8 about here]}

The first thing we observe is that the results are very similar for the stock prices and logged stock prices, and the unit root null hypothesis of $d=b=1$ cannot be rejected in the first, second, third and last (xixth) subsamples, while it is rejected in favour of smaller degrees of integration in the fourth and fifth subsamples. For the betas, the degree of integration is smaller in all cases increasing sharply during the last two subsamples. This variability in the behaviour in the analyzed periods could be caused by the high instability and by the number of data used in the analysis.

Next we examine how the price of oil (WTI) affects the behaviour of each company dedicated to lithium mining and then the behaviour of the lithium industry in general. Figures 2 - 5 display the wavelet coherency and the phase difference for the stock prices of each of the U.S. lithium mining companies that together represent $53 \%$ of the market, and WTI crude oil prices in daily frequency data, showing evidence of varying dependence between both time series across different frequencies and over time. 
The left panel (a) displays the wavelet coherency between each U.S. lithium mining company, including the Solactive Global Lithium Index and WTI crude oil prices. Frequencies are shown on the vertical axis, from scale 1 (a single day) up to scale 512 (approximately two market years), whereas time is shown in the horizontal axis, from the beginning to the end of the sample period. The statistical significance of local correlations in the time-frequency domain was evaluated using Monte Carlo simulations. The regions surrounded by the black contour are the high coherence regions with significant values at $5 \%$, which are the obtained outcomes.

This analysis presents regions in time-frequency space where two time series are highly dependent, plotting those regions with cooler colors and plotting less dependence using warmer colors. The right panel has the phase differences: on the top (b) is the phase difference in the 1.5-31.5 frequency band for daily data; at the bottom (c) is the phase difference in the 32-512 frequency band for daily data. The frequency band helps to understand the movement of both time series, one in relation to the other.

\section{[Insert Figure 2 about here]}

Analyzing the wavelet coherency between the stock prices of the firm Albemarle and WTI crude oil prices (in Figure 2), we appreciate that the time series were weakly related at the short-time (higher frequencies) and this weakness persists throughout the sample period. However, at lower frequencies, WTI crude oil prices dependence on the lithium industry increased. In the case of the first examined firm, Albemarle, the level of dependence starts in late 2012, reaching high levels of dependence centered at lower frequencies (from 240 to 275 days) in the year 2015. In the same year, 2015, the degree of dependence changed, reaching high levels of dependence in the same lower frequencies (from 48 to 96 days) in early 2016. After 2016 dependence for both the short and the long run dissipated. 
Focusing now on the phase difference during the period of dependence, between 0 and $\pi / 2$, the correlation of the series is positive, and they move together, suggesting that the WTI crude oil prices are lagging behind the Albemarle stock prices.

\section{[Insert Figure 3 about here]}

In the case of the FMC Corporation stock prices versus WTI oil prices and analyzing the wavelet coherency between the two (in Figure 3), we can conclude by saying that the level of dependence starts in early 2014, reaching high levels of dependence centered at lower frequencies (from 64 to 128 days) in mid-2016. Analyzing the phase difference during the period of dependence, the same pattern is seen as with the other security: the correlation of the two series suggests that WTI crude oil prices are influencing FMC stock prices in mid-2015.

\section{[Insert Figure 4 about here]}

Finally, analyzing Figure 4 which corresponds to SQM stock prices and WTI oil prices and analyzing the wavelet coherency between the two, we observe that the level of dependence in this case occurs at lower frequencies than in the other two cases. The highest level of dependence occurred in 2015 centered at lower frequencies, from 48 to 67 days. Analyzing the phase difference, we conclude that the correlation of the two time series suggests that WTI crude oil prices are influencing FMC stock prices by early-2015.

Figure 5 displays the wavelet coherency and the phase difference for the daily prices of Solactive Lithium Index and WTI crude oil prices, showing evidence of varying dependence between the two time series across different frequencies and over time.

\section{[Insert Figure 5 about here]}

Analyzing the wavelet coherency between Solactive Global Lithium Index and WTI crude oil prices, we notice that the time series were weakly related at higher frequencies and this weakness persisted throughout the sample period. However, at lower 
frequencies, WTI crude oil prices dependence on lithium industry increased. The level of dependence starts in early 2014, reaching high levels of dependence centred at lower frequencies (from 48 to 70 days) in the year 2015. After 2015 dependence for both the short and the long run dissipated. The phase difference during the period of dependence is between 0 and $\pi / 2$, the correlation of the series is positive, and they move together, suggesting that the WTI crude oil prices are lagging behind the lithium industry. The policy and prices of alternative fuels and vehicles could be behind this result. A process of technological transition could very well upend the oil sector, suggesting that alternative energy sources and storage such as lithium could produce oil demand to peak.

Identical results using this wavelet approach were obtained when using data with weekly and monthly frequencies and they are not reported in the paper though are available from the authors upon request.

These results are in line with the statement made by Cherif and Hasanov (2017) about the third energy transition and renewable energies in relation to the transport sector, in which $35 \%$ of all new cars by 2040 will be powered by electricity bringing about the next oil crisis (see Randall, 2016). Finally, BP (2020) ruled in its report that the liquid fuel demand is dominated by the electrification of transport thanks in part to the lithium industry that is causing falls in the demand for transport fuel in the developed world of around $90 \%$.

\section{Concluding comments}

We have examined in this article the interconnections between lithium mining companies in the U.S. and their beta risk, the lithium industry and WTI crude oil prices. In doing so we have investigated what type of relationship exists between them in the long run in order to know if lithium is really a substitute for oil. 
For this purpose, we have selected the largest lithium mining companies listed in the U.S. per market capitalization, market share and which are listed in the stock markets, calculating daily, weekly and monthly betas for each one. Finally, to analyze the lithium industry and crude oil prices, we have used Solactive Lithium Index and West Texas Intermediate crude oil prices, respectively. On the other hand, we have also used ARFIMA (p, d, q) models to measure the degree of persistence and calculate the differencing parameter of each series. Using three different time frequencies (daily, weekly and monthly) we get the same results, in which the behaviour of the beta of the company FMC supports the unit root or I(1) hypothesis, while the betas of the companies Albermarle and SQM are $\mathrm{I}(\mathrm{d}, \mathrm{d}<1)$, implying fractional integration and mean reverting behaviour, with shocks having temporary effects and disappearing in the long run.

Using the Fractional Cointegration Vector AutoRegressive (FCVAR) approach we find evidence of cointegration and thus in the long term there should not be any deviations in the stock prices. The same results are obtained when using data for the beta term structure though the order of integration is then found to be slightly smaller.

Perfoming tests for structural breaks, five breaks were found in the three series and though there is some instability across the subsamples, the FCVAR approach was supported for the stock prices and logged stock prices with orders of integration around 1 and being lower in case of the beta series.

Finally, we have used Continuous Wavelet Transform (CWT) techniques to study the main components of the stock prices of lithium mining companies, the lithium industry and WTI crude oil prices in the time-frequency space. The common result obtained in this work is that, for the cases of stock prices of lithium mining companies and the lithium industry with WTI, crude oil prices have the same behaviour, with the relationship between these time series weakly related at higher frequencies (short-run) 
and the weakness persisting throughout the sample period. Also, at lower frequencies (long-term), WTI crude oil prices dependence on lithium securities and the lithium industry increased, on average, in late 2012, reaching the highest levels of dependence in the year 2016. After this, the dependence dissipated. Analyzing the phase difference, we can conclude that the lithium mining companies and the lithium industry reflect and foreshadow the responsiveness of the WTI crude oil prices during the period mentioned above. Similar results were obtained when we use weekly and monthly frequency data arriving at the same conclusion as Momcilovic, et al. (2014) who stated that there are no statistically significant differences between betas calculated on the basis of daily, weekly and monthly return intervals.

According to Cherif and Hasanov (2017), this behaviour of the largest lithium mining companies and the effects in the long-run of the lithium industry and WTI crude oil prices localized in the wavelet coherence could be explained by the third energy transition and with the renewable energies in relation to the transport sector. Randall (2016) predicts that $35 \%$ of all new cars by 2040 will be powered by electricity and this rapid transformation from regular gasoline driven cars to EVs may be enough to cause the next oil crisis. On the other hand, BP (2020), in the Energy Outlook, concludes that the demand for oil for transportation in emerging markets will continue to increase until the early 2030s but this is increasingly offset by falls in the developing world since the share of oil in total final consumption has fallen from over $90 \%$ of transport demand in 2018 due to the increasing use of electricity, especially in passenger cars and light and medium-duty trucks. BP (2020) concludes in this outlook that liquid fuel demand is dominated by the electrification of transport thanks in part to the lithium industry as the authors in this research paper state. 
This paper can be very helpful to institutions and companies that are exposed to crude oil market changes. Our findings might help market participants to understand better what the impact of the lithium industry on crude oil price movements may be and its subsequent potential effects on hedging strategies. It would be also reasonable to extend this research to other influence groups in the oil industry or high producing countries such as OPEC countries, the U.S. or Russia. 


\section{References}

Aguiar-Conraria, L., Azevedo, N., Soares, M. J. 2008. Using wavelets to decompose the time-frequency effects of monetary policy. Physica A: Statistical Mechanics and its Applications, 387, 2863-2878.

Aguiar-Conraria, L., and Soares, M. J. 2011. Oil and the macroeconomy: using wavelets to analyze old issues. Empirical Economics, 40, 645-655.

Aguiar-Conraria, L., and Soares, M. J. 2014. The continuous wavelet transform: moving beyond uni- and bivariate analysis. Journal of Economic Survey, 28, 344-375.

Akaike, H. (1973). Maximum likelihood identification of Gaussian autoregressive moving average models. Biometrika, 60(2), 255-265.

Akaike, H. (1979). A Bayesian extension of the minimum AIC procedure of autoregressive model fitting. Biometrika, 66(2), 237-242.

Anderson, C. D., and Anderson, J. (2010). Electric and hybrid cars: A history. McFarland.

Apergis, N., Christou, C., \& Payne, J. E. (2014). Precious metal markets, stock markets and the macroeconomic environment: a FAVAR model approach. Applied Financial Economics, 24(10), 691-703.

Auer, B. R. (2015). Superstitious seasonality in precious metals markets? Evidence from GARCH models with time-varying skewness and kurtosis. Applied Economics, 47(27), 2844-2859.

Aye, G. C., Carcel, H., Gil-Alana, L. A., Gupta, R. 2017. Does gold act as a hedge against inflation in the UK? Evidence from a fractional cointegration approach over 1257 to 2016. Resources Policy, 54, 53-57.

Bai, J., and P. Perron, 2003. Computation and analysis of multiple structural change models. Journal of Applied Econometrics 18, 1-22.

Bannigidadmath, D., \& Narayan, P. K. (2016). Stock return predictability and determinants of predictability and profits. Emerging Markets Review, 26, 153-173.

Baruník, J., Dvořáková, S. 2015. An empirical model of fractionally cointegrated daily high and low stock market prices. Economic Modelling, 45, 193-206.

Berthelsen, J. H. S., \& Arteaga, A. (2016). What relationship exists between oil prices, lithium prices and electric vehicle Growth: Is lithium really becoming a substitute for oil? (Master's thesis, BI Norwegian Business School).

BP Energy Outlook, 2017. https://www.bp.com/content/dam/bp/pdf/energyeconomics/energy-outlook-2017/bp-energy-outlook-2017.pdf.

BP Energy Outlook, 2020. https://www.bp.com/en/global/corporate/energyeconomics/energy-outlook.html 
Cherif, R., Hasanov, F. 2017. Riding the Energy Transition: Oil Beyond 2040. IMF Working Paper.

Ciner, C. (2001). On the long run relationship between gold and silver prices A note. Global Finance Journal, 12(2), 299-303.

Connor, J., \& Rossiter, R. (2005). Wavelet transforms and commodity prices. Studies in Nonlinear Dynamics \& Econometrics, 9(1).

Crowley, P. M., \& Mayes, D. G. (2009). How fused is the Euro area core?: an evaluation of growth cycle co-movement and synchronization using wavelet analysis. $O E C D$ Journal: Journal of Business Cycle Measurement and Analysis, 2008(1), 63-95.

Cuestas, J.C. and L.A. Gil-Alana (2016) A Non-Linear Approach with Long Range Dependence Based on Chebyshev Polynomials, Studies in Nonlinear Dynamics and Econometrics 23, 445-468.

Davidson, R., Labys, W. C., Lesourd, J. B. 1997. Wavelet analysis of commodity price behavior. Computational Economics, 11, 103-128.

Dewandaru, G., Masih, R., \& Masih, A. M. M. (2016). Contagion and interdependence across Asia-Pacific equity markets: An analysis based on multi-horizon discrete and continuous wavelet transformations. International Review of Economics \& Finance, 43, 363-377.

Dickey, D.A and Fuller, W. A. (1979) Distributions of the estimators for autoregressive time series with a unit root, Journal of American Statistical Association, 74 (366), 427481.

Diebold, F.X, and G. Rudebush (1991), "On the power of the Dickey-Fuller tests against fractional alternatives”, Economic Letters, 35, 55-160.

Dolatabadi, S., Narayan, P. K., Nielsen, M. Ø., Xu, K. 2018. Economic significance of commodity return forecasts from the fractionally cointegrated VAR model. Journal of Futures Markets, 38(2), 219-242.

Dooley, G., \& Lenihan, H. (2005). An assessment of time series methods in metal price forecasting. Resources Policy, 30(3), 208-217.

Elliot, G., T.J. Rothenberg, and J.H. Stock, (1996), Efficient tests for an autoregressive unit root, Econometrica 64, 813-836.

Fouquet, R. 2010. The slow search for solutions: Lessons from historical energy transitions by sector and service. Energy Policy, 6586-6596.

Fouquet, R. 2016. Lessons from energy history for climate policy: Technological change, demand and economic development. Energy Research \& Social Science, 22, 79-93. 
Freitas, C. J. P., \& Da Silva, P. P. (2013). Evaluation of dynamic pass-through of carbon prices into electricity prices-a cointegrated VECM analysis. International Journal of Public Policy 14, 9(1-2), 65-85.

Fuller, W. A. (1976). Introduction to Statistical Time Series, New York: JohnWiley. FullerIntroduction to Statistical Time Series 1976.

Geweke, J., \& Porter-Hudak, S. (1983). The estimation and application of long memory time series models. Journal of time series analysis, 4(4), 221-238.

Gil-Alana, L. A. (2008). Fractional integration and structural breaks at unknown periods of time. Journal of Time Series Analysis, 29(1), 163-185.

Gil-Alana, L. A., Carcel, H. 2018. A fractional cointegration var analysis of exchange rate dynamics. The North American Journal of Economics and Finance.

Gil-Alana, L. A., Monge, M. 2019. Lithium: Production and estimated consumption. Evidence of persistence. Resources Policy, 60, 198-202.

Gil-Alana, L.A. and P.M. Robinson, (1997), Testing of unit roots and other nonstationary hypothesis in macroeconomic time series, Journal of Econometrics 80, 2, 241-268.

Gu, G. F., \& Zhou, W. X. (2010). Detrending moving average algorithm for multifractals. Physical Review E, 82(1), 011136.

Hao, H., Geng, Y., Sarkis, J., 2016. Carbon footprint of global passenger cars: scenarios through 2050. Energy, 101, 121-131.

Hassler, U. and J. Wolters, 1994, On the power of unit root tests against fractional alternatives, Economics Letters 45, 1-5.

IPCC fourth assessment report: mitigation of climate change; 2007. http://www.ipcc.ch/pdf/assessment-report/ar4/wg3/ar4-wg3-chapter5.pdf.

Jammazi, R., Ferrer, R., Jareño, F., \& Shahzad, S. J. H. (2017). Time-varying causality between crude oil and stock markets: What can we learn from a multiscale perspective? International Review of Economics \& Finance, 49, 453-483.

Jiang, Z. Q., \& Zhou, W. X. (2011). Multifractal detrending moving-average crosscorrelation analysis. Physical Review E, 84(1), 016106.

Johansen, S. 1996. Likelihood-based inference in cointegrated vector autoregressive models. New York, NY: Oxford University Press.

Johansen, S. 2008. A representation theory for a class of vector autoregressive models for fractional processes. Econometric Theory, 24, 651-676.

Johansen, S., Nielsen, M. Ø. 2010. Likelihood inference for a nonstationary fractional autoregressive model. Journal of Econometrics, 158, 51-66. 
Johansen, S., Nielsen, M. Ø. 2012. Likelihood inference for a fractionally cointegrated vector autoregressive model. Econometrica, 80, 2667-2732.

Jones, M. E., Nielsen, M. Ø., Popiel, M. K. 2014. A fractionally cointegrated VAR analysis of economic voting and political support. Canadian Journal of Economics, 47, 1078-1130.

Khondekar, M. H., Ghosh, D. N., Ghosh, K., \& Bhattacharya, A. K. (2012). An investigation on the relationship between solar irradiance signal from ERBS and 8 B solar neutrino flux signals from SNO. Astrophysics and Space Science, 342(2), 287-301.

Kilian, L. (2016). The impact of the shale oil revolution on US oil and gasoline prices. Review of Environmental Economics and Policy, 10(2), 185-205.

Kilian, L. (2017). The impact of the fracking boom on Arab oil producers. The Energy Journal, 38(6).

Kwiatkowski D, P.C.D Phillips, P. Schmidt, Y. Shin, (1992), Testing the null hypothesis of stationarity against the alternative of a unit root: How sure are we that economic time series have a unit root?, Journal of Econometrics 54, 159-178.

Kyrtsou, C., Malliaris, A. G., \& Serletis, A. (2009). Energy sector pricing: On the role of neglected nonlinearity. Energy Economics, 31(3), 492-502.

Labys, W. C., Lesourd, J. B., \& Badillo, D. (1998). The existence of metal price cycles. Resources policy, 24(3), 147-155.

Lee, D. and P. Schmidt, 1996, On the power of the KPSS test of stationarity against fractionally integrated alternatives, Journal of Econometrics 73, 285-302.

Maciel, L. 2017. Technical analysis based on high and low stock prices forecasts: Evidence for Brazil using a fractionally cointegrated VAR model. Empirical Economics, $1-28$.

MacKinnon, J.G., Nielsen, M.Ø., 2014. Numerical distribution functions of fractional unit root and cointegration tests. Journal of Applied Econonomics, 29, 161-171.

Martin, G., Rentsch, L., Höck, M., \& Bertau, M. (2017). Lithium market research-global supply, future demand and price development. Energy Storage Materials, 6, 171-179.

Mo, J. Y., \& Jeon, W. (2018). The impact of electric vehicle demand and battery recycling on price dynamics of lithium-ion battery cathode materials: A vector error correction model (VECM) analysis. Sustainability, 10(8), 2870.

Momcilovic, M., Begovic, S. V., \& Tomasevic, S. (2014). Influence of return interval on stock's beta. Advances in Economics, Law and Political Science, 168-171.

Monge, M., Gil-Alana, L. A., de Gracia, F. P. 2017. U.S. shale oil production and WTI prices behaviour. Energy, 141, 12-19. 
Monge, M., Gil-Alana, L. A. 2018. Lithium industry in the behavior of the mergers and acquisitions in the US oil and gas industry. Energy Sources, Part B: Economics, Planning, and Policy, 13, 392-403.

Monge, M., Gil-Alana, L. A. 2019. Automobile components: Lithium and cobalt. Evidence of persistence. Energy, 169, 489-495.

Monge, M., Gil-Alana, L. A. 2020. The Lithium Industry and Analysis of the Beta Term Structure of Oil Companies. Risks, 8, 130.

Nakicenovic, N. (1986). The automobile road to technological change: diffusion of the automobile as a process of technological substitution. Technological Forecasting and Social Change, 29(4), 309-340.

Nasdaq (2018). SQM vs Albemarle vs FMC Corp.: Which had the best lithium results in Q2?. https://www.nasdaq.com/articles/sqm-vs-albemarle-vs-fmc-corp-which-had-bestlithium-results-q2-2018-09-20.

Nielsen, M. Ø., Popiel, M. K. 2018. A Matlab program and user's guide for the fractionally cointegrated VAR model (Queen's Economics Department Working Paper No 1330). Ontario, Canada, K7L 3N6.

Ng, S. and P. Perron,. (2001), Lag length selection and the construction of unit root tests with good size and power, Econometrica 69, 519-1554

Pal, D., \& Mitra, S. K. (2019). Oil price and automobile stock return co-movement: A wavelet coherence analysis. Economic Modelling, 76, 172-181.

Perron, P. (1997), Further evidence on braking trend functions in macroeconomic variables, Journal of Econometrics 80, 355-385.

Perron, P. and T.J. Vogelsang (1992), Testing for a Unit Root in a Time Series with a Changing Mean: Corrections and Extensions, Journal of Business and Economic Statistics 10, 4, 467-470.

Phillips, P.C.B. and P. Perron, (1988), Testing for a unit root in time series regression, Biometrika 75, 335-346.

Phillips, P. C. B. (1999). Discrete Fourier transforms of fractional processes. Department of Economics, University of Auckland.

Phillips, P. C. B. (2007). Unit root log periodogram regression. Journal of econometrics, 138(1), 104-124.

Podobnik, B., \& Stanley, H. E. (2008). Detrended cross-correlation analysis: a new method for analyzing two nonstationary time series. Physical review letters, 100(8), 084102 . 
PwC, 2016. 2016 Auto industry trends: Automakers and suppliers can no longer sit out the industry's transformation. http://www.strategyand.pwc.com/media/file/2016-AutoTrends.pdf.

Randall, T. (2016) "Here's How Electric Cars Will Cause the Next Oil Crisis" Bloomberg.com, 25 Feb, http://www.bloomberg.com/features/2016-ev-oilcrisis/, Retrieved: 22.06.2016

Rossen, A. (2015). What are metal prices like? Co-movement, price cycles and long-run trends. Resources Policy, 45, 255-276.

Sari, R., Hammoudeh, S., \& Soytas, U. (2010). Dynamics of oil price, precious metal prices, and exchange rate. Energy Economics, 32(2), 351-362.

Schurr, S. H., Netschert, B. C. 1960. Energy in the American economy, 1850-1975 (Vol. 960). Baltimore.

Sovacool, B. K. 2016. How long will it take? Conceptualizing the temporal dynamics of energy transitions. Energy Research \& Social Science, 13, 202-215.

Sowell, F. (1992). Modeling long-run behavior with the fractional ARIMA model. Journal of Monetary Economics, 29(2), 277-302.

Tiwari, A. K., Mutascu, M. I., \& Albulescu, C. T. (2016). Continuous wavelet transform and rolling correlation of European stock markets. International Review of Economics \& Finance, 42, 237-256.

Vacha, L., and Barunik, J. 2012. Co-movement of energy commodities revisited: Evidence from wavelet coherence analysis. Energy Economics, 34, 241-247.

Yousefi, S., Weinreich, I., Reinarz, D. 2005. Wavelet-based prediction of oil prices. Chaos, Solitons \& Fractals, 25, 265-275.

Zhou, W. X. (2008). Multifractal detrended cross-correlation analysis for two nonstationary signals. Physical Review E, 77(6), 066211. 


\section{DATA AVAILABILITY STATEMENT}

The data that support the findings of this study are available from the corresponding author upon reasonable request. 
Table 1: market capitalization and market share of the selected companies

\begin{tabular}{|c|c|c|}
\hline & Market Capitalization ${ }^{1}$ & Market Share $^{2}$ \\
\hline Albemarle & 10.801 & $19 \%$ \\
\hline SQM & 8.383 & $17 \%$ \\
\hline FMC & 1.271 & $10 \%$ \\
\hline
\end{tabular}

Table 2: Unit root test results

\begin{tabular}{lccccccc}
\hline & \multicolumn{3}{c}{ ADF } & \multicolumn{3}{c}{ PP } & \multicolumn{2}{c}{ KPSS } \\
\hline \hline & (i) & (ii) & (iii) & (i) & (ii) & (i) & (ii) \\
\hline B_Albemarle & -1.3539 & -6.3667 & -6.3398 & -5.2318 & -5.226 & 2.2104 & 2.0086 \\
B_FMC & -0.9916 & 0.9742 & 1.3802 & 1.6276 & 2.1286 & 3.7784 & 2.7784 \\
B_SQM & -0.9075 & -4.7906 & -6.0316 & -5.3538 & -6.7903 & 11.9994 & 1.1056 \\
\hline & & \multicolumn{7}{c}{ Weekly Results } \\
\hline B_Albemarle & -0.4848 & -5.7592 & -6.4097 & -5.6042 & -6.3735 & 2.3056 & 0.4074 \\
B_FMC & -1.1104 & 2.951 & 3.069 & 5.2243 & 5.7481 & 0.1233 & 0.1362 \\
B_SQM & -0.1775 & -5.032 & -5.5701 & -5.5082 & -6.1375 & 1.3753 & 0.1639 \\
\hline & & \multicolumn{7}{c}{ Monthly Results } & & & \\
\hline B_Albemarle & 0.1484 & -1.2348 & -0.0742 & -2.038 & -1.1703 & 0.5462 & 0.1253 \\
B_FMC & -0.3567 & -1.2101 & -2.1418 & -3.5027 & -3.7245 & 0.8972 & 0.3315 \\
B_SQM & -0.6532 & -2.2219 & -2.767 & -3.6062 & -4.9946 & 0.9172 & 0.2393 \\
\hline
\end{tabular}


Table 3: Fractional Integration results

\begin{tabular}{|c|c|c|c|c|c|}
\hline Data analyzed & Model Selected & $d$ & Std. Error & Interval & $\mathrm{I}(\mathrm{d})$ \\
\hline \multicolumn{6}{|c|}{ Daily Results } \\
\hline B_Albemarle & $\operatorname{ARFIMA}(2, \mathrm{~d}, 2)$ & 0.74 & 0.038 & {$[0.68,0.80]$} & $\mathrm{I}(\mathrm{d})$ \\
\hline B_FMC & $\operatorname{ARFIMA}(2, \mathrm{~d}, 2)$ & 0.99 & 0.025 & {$[0.95,1.03]$} & $\mathrm{I}(1)$ \\
\hline B_SQM & $\operatorname{ARFIMA}(1, d, 1)$ & 0.61 & 0.055 & {$[0.55,0.70]$} & $\mathrm{I}(\mathrm{d})$ \\
\hline \multicolumn{6}{|c|}{ Weekly Results } \\
\hline B_Albemarle & $\operatorname{ARFIMA}(2, \mathrm{~d}, 2)$ & 0.60 & 0.036 & {$[0.54,0.66]$} & $\mathrm{I}(\mathrm{d})$ \\
\hline B_FMC & $\operatorname{ARFIMA}(2, \mathrm{~d}, 0)$ & 1.35 & 0.043 & {$[1.28,1.42]$} & $\mathrm{I}(1)$ \\
\hline B_SQM & $\operatorname{ARFIMA}(2, \mathrm{~d}, 2)$ & 0.88 & 0.057 & {$[0.79,0.98]$} & $\mathrm{I}(\mathrm{d})$ \\
\hline \multicolumn{6}{|c|}{ Monthly Results } \\
\hline B_Albemarle & $\operatorname{ARFIMA}(0, \mathrm{~d}, 0)$ & 0.54 & 0.1921 & {$[0.22,0.85]$} & $\mathrm{I}(\mathrm{d})$ \\
\hline B_FMC & $\operatorname{ARFIMA}(1, \mathrm{~d}, 1)$ & 1.02 & 0.243 & {$[0.62,1.42]$} & $\mathrm{I}(1)$ \\
\hline B_SQM & $\operatorname{ARFIMA}(1, d, 0)$ & 0.75 & 0.133 & {$[0.53,0.97]$} & $\mathrm{I}(\mathrm{d})$ \\
\hline
\end{tabular}


Table 4. Fractionally Cointegrating Vector Autorregression: Estimation Results.

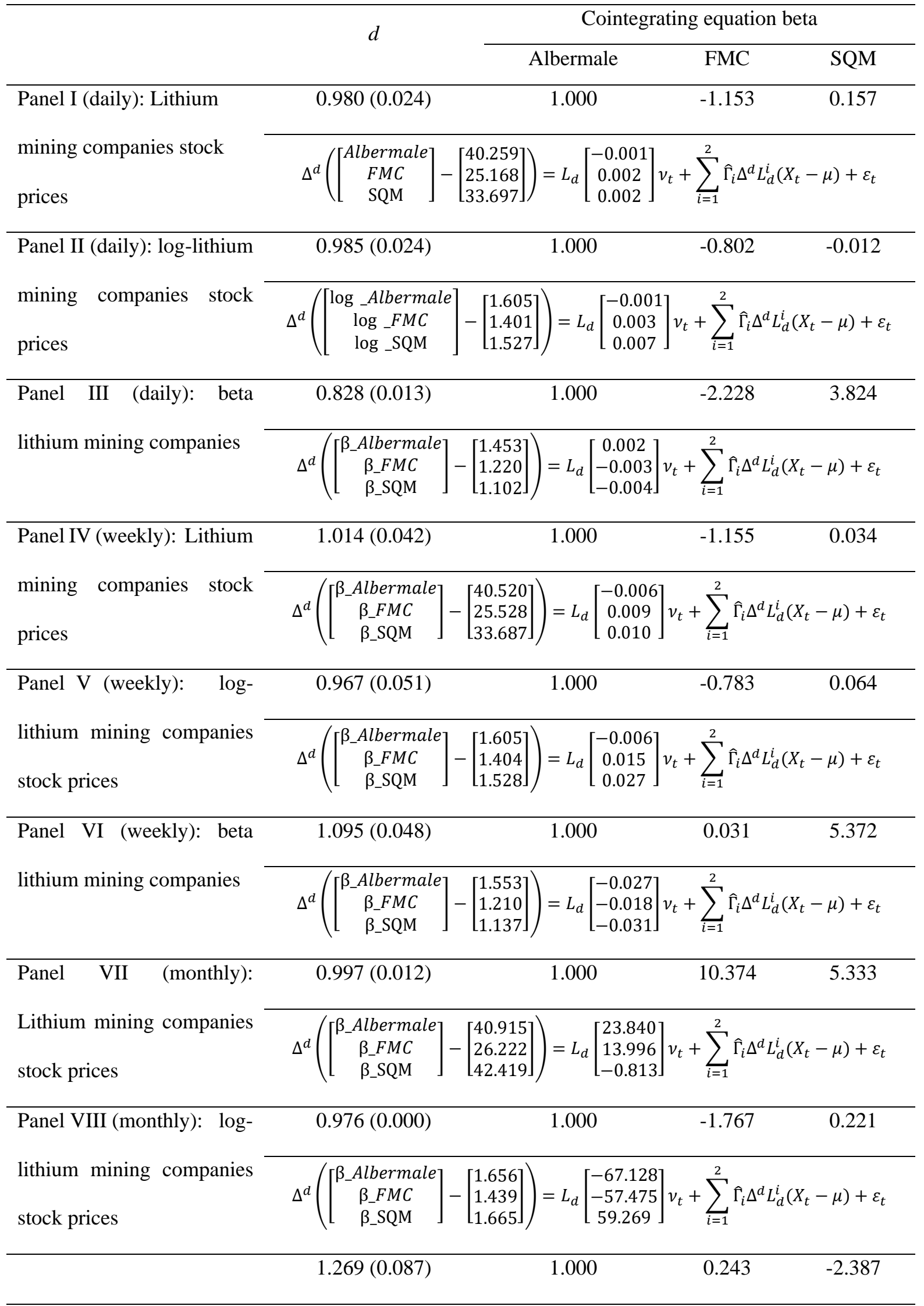




\begin{tabular}{ll}
\hline Panel IX (monthly): beta & $\Delta^{d}\left(\left[\begin{array}{c}\beta_{-} \text {Albermale } \\
\beta_{-} F M C \\
\beta_{-} S Q M\end{array}\right]-\left[\begin{array}{c}1.613 \\
1.296 \\
1.339\end{array}\right]\right)=L_{d}\left[\begin{array}{c}-0.088 \\
-0.094 \\
0.198\end{array}\right] v_{t}+\sum_{i=1}^{2} \hat{\Gamma}_{i} \Delta^{d} L_{d}^{i}\left(X_{t}-\mu\right)+\varepsilon_{t}$ \\
lithium mining companies
\end{tabular}

Table 5: Structural breaks

\begin{tabular}{lcc}
\hline Series & No. of & Break dates \\
& breaks & $02.11 .2011 ; 26.06 .2013 ; 27.11 .2014 ;$ \\
WTI crude oil prices & 5 & $13.05 .2016 ; 02.11 .2017$ \\
\hline
\end{tabular}

Table 6. Fractionally Cointegrating Vector Autorregression: Estimation Results for the structural breaks in stock prices.

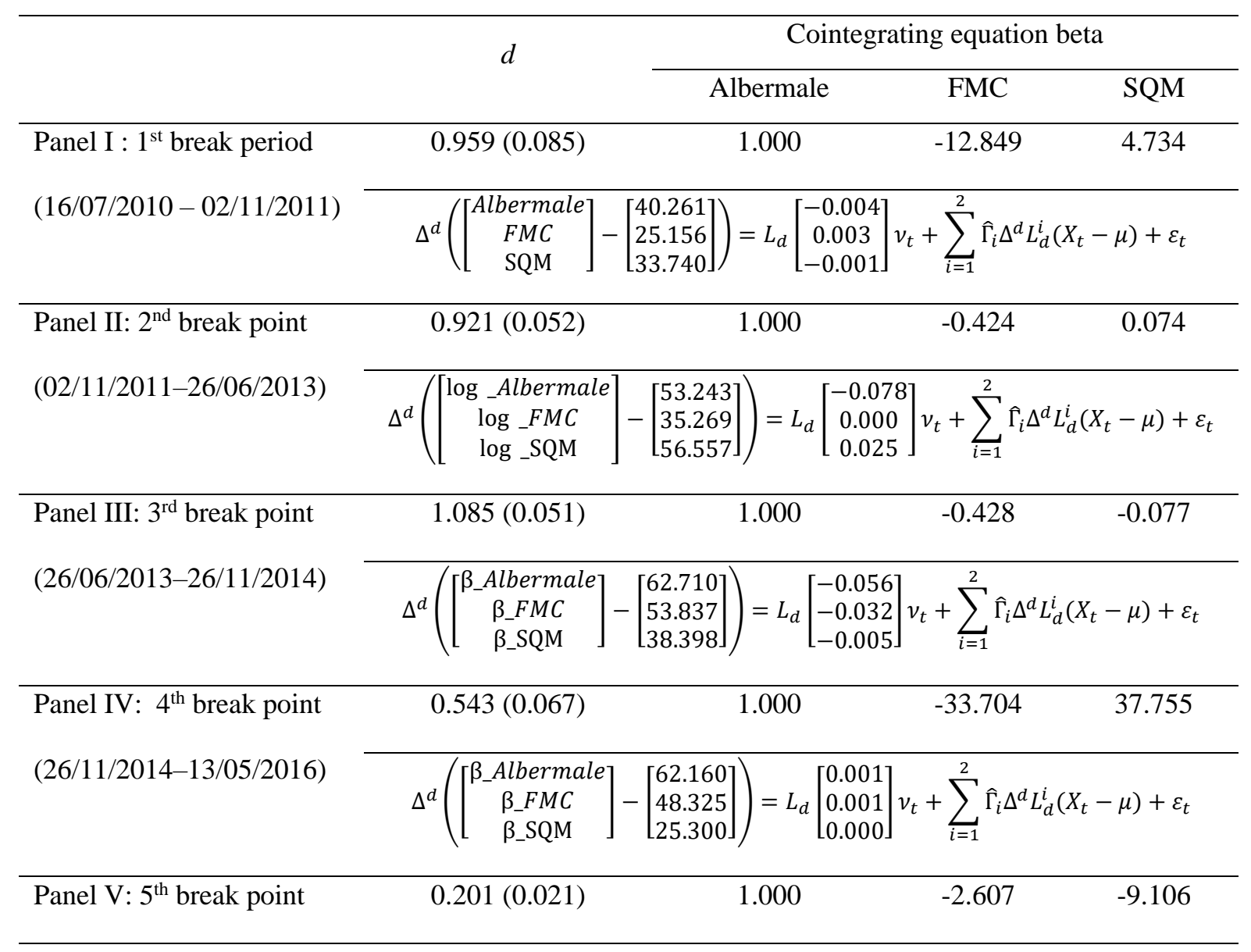




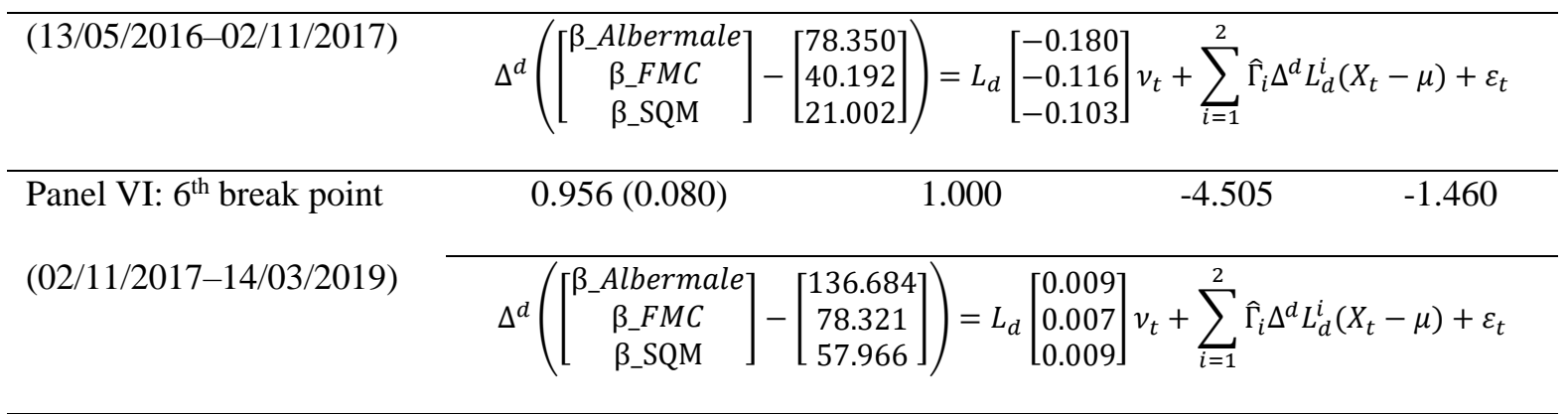

Table 7. Fractionally Cointegrating Vector Autorregression: Estimation Results for the structural breaks in log stock prices.

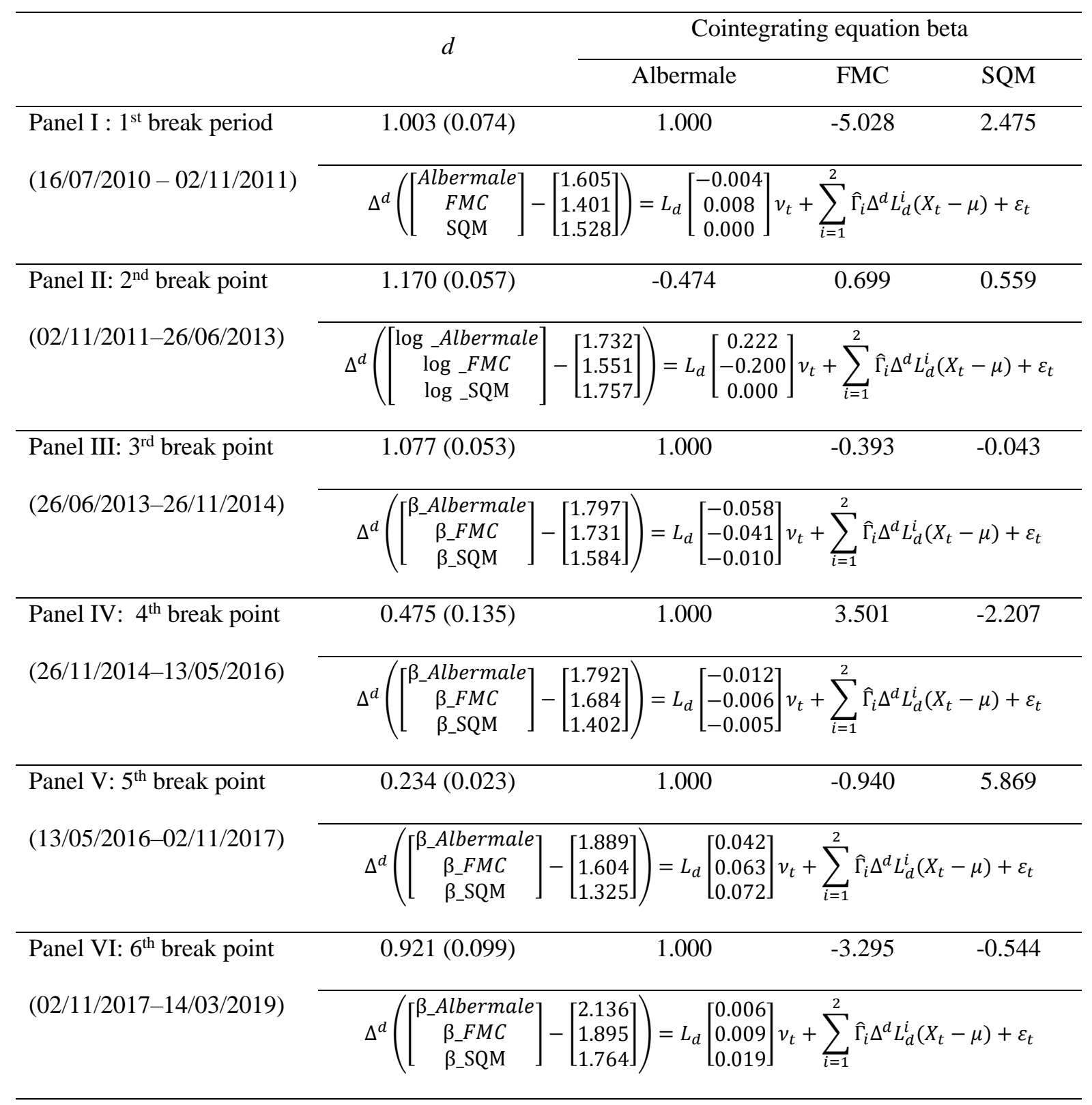


Table 8. Fractionally Cointegrating Vector Autorregression: Estimation Results for the structural breaks in beta term.

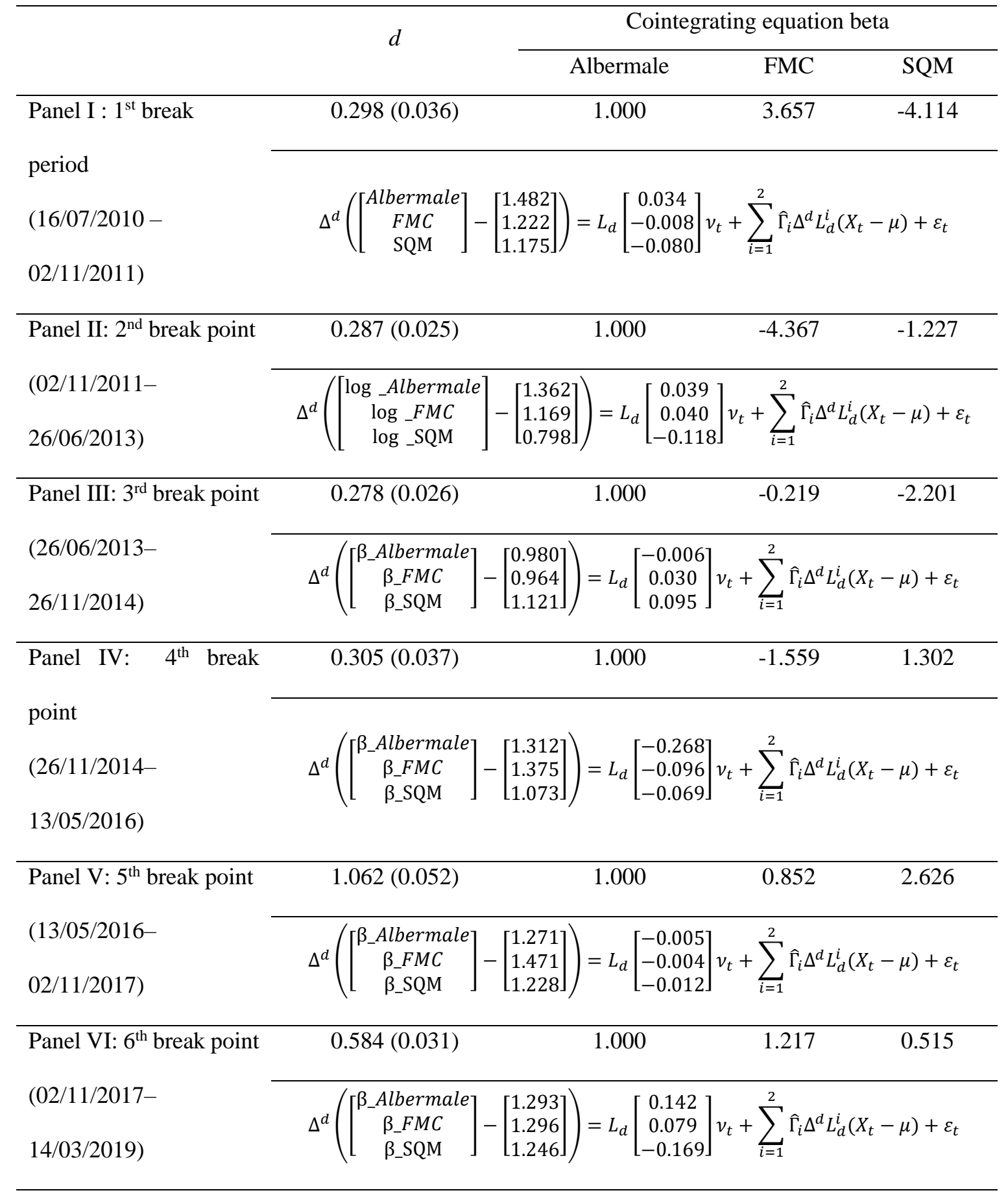

